\title{
LÍNGUAS AMERÍNDIAS: MODOS E CAMINHOS DA TRADUÇÃO
}

\author{
Bruna Franchetto \\ Museu Nacional/Universidade Federal do Rio de Janeiro \\ bfranchetto@yahoo.com.br
}

Resumo: A partir de um esforço de sistematização de observações esparsas e de uma longa experiência de estudo de línguas ameríndias faladas no Brasil, este texto enfoca aspectos do trabalho de tradução que atravessa todo o processo da pesquisa linguística e etnográfica. Entendendo tradução no sentido mais amplo possível, são abordados diferentes temas interrelacionados, tomando como caso em análise exercícios tradutivos entre uma língua karib do Alto Xingu - o Kuikuro - e o português. O primeiro tema é o da transformação de falas e artes verbais de tradição oral em textos escritos, passo que antecede qualquer forma de tradução propriamente dita. O segundo tema concerne a produção escrita e a tradução induzidas pela escolarização e pelas demandas do pesquisador. O terceiro tema, inevitável, é o trabalho de tradução motivado pelo contato com missionários. Existem nexos entre essas operações de transfiguração do exótico em familiar e vice-versa, e as pretensões 'civilizatórias' de missionários, agentes da escolarização e pesquisadores, uma armadilha pronta a engolir mesmo os tradutores, indígenas e não-indígenas, mais bem intencionados. Palavras-chave: Línguas ameríndias, tradução, escrita, poética oral, artes verbais

\section{AMERINDIAN LANGUAGES: MODES AND WAYS OF TRANSLATION}

\footnotetext{
Abstract: As an effort to organize scattered observations and as a result of a long experience of investigation of Amerindian languages spoken in Brazil, this essay deals with some aspects of the work of translation that goes through the whole process of the linguistic and ethnographic
} 
research. Once translation is understood in its widest meaning, different interrelated topics are approached, taking as the case under scrutiny the translation between Kuikuro, a Karib language spoken in the Upper Xingu region, and Portuguese. The first topic is the transformation of speeches and verbal arts coming from an oral tradition into written texts, a step that precedes any formalized interlinguistic translation. The second topic concerns the written products and the translation induced by schooling and by the demands coming from the researcher. The third and unavoidable topic is the translation work induced by the contact with missionaries. There are connections between these transmutative operations from exotic to familiar, and vice-versa, and the 'civilizing' pretentions of missionaries, school's agents, and researchers, a trap ready to even the most wellmeaning translators, be they Amerindian or not.

Keywords: Amerindian languages, translation, writing, oral poetics, verbal arts

Este texto tomou forma ao reunir observações, em aparência fragmentadas, e memórias de uma longa experiência em que o processo tradutivo sempre esteve presente, antes em segundo plano, nos bastidores não explícitos de uma pesquisa linguística e etnográfica, depois, e mais recentemente, assumindo a relevância de um objeto claro de reflexão.

Em mais de trinta anos de estudos de línguas ameríndias faladas em território brasileiro, acumulei experiências de tradução ao transformar falas e artes da palavra em textos escritos, mutilando a multidimensionalidade da oralidade, ao tentar transpô-las para outra língua, muito distante, ao interpretar conceitos, explanações, histórias de vida, ao alfabetizar, ensinar, orientar jovens índios até a pós-graduação, quando me empenhei em traduzir em sentido inverso, do 'nosso' mundo ao 'deles'. De algum modo, persegui um equilíbrio, sempre em devir e instável, entre os dois caminhos, de lá para cá, de cá para lá, digamos.

Não pretendo discorrer sobre teorias da tradução, por não ter a competência específica e para além de algumas citações e referências. Quero, apenas, oferecer pinceladas de uma vivência, que possam me ajudar a sistematizar, minimamente, observações 
esparsas, e, quem sabe, se tornar insumo para todos os que, consciente ou inconscientemente, operam traduções de línguas indígenas. Existem nexos nada desprezíveis entre essas operações, no fio da transfiguração do exótico em familiar e vice-versa, e as pretensões 'civilizatórias', mascaradas ou não, de missionários, agentes da escolarização e até pesquisadores. Tentei me afastar dessa armadilha em minha prática tradutiva, mas o risco e o medo de cair nela nunca me abandonaram e nunca me abandonam.

Finalmente, o que aqui escrevo reflete também outra experiência, a de um curso, cujo título coincide com o deste texto, por mim ministrado durante o primeiro semestre de 2011, particularmente nos seis seminários realizados no âmbito do curso sob a batuta de convidados especiais ${ }^{1}$.

\section{Escrita como tradução}

A escrita se pretende 'civilizatória', aniquila formas e mecanismos de memorização e de transmissão inerentes à oralidade - como já dizia um Platão conservador, quando as Musas aprenderam a escrever -, imobiliza o movimento das versões, do dizer, cristaliza palavras e construções. Quase nada sabemos sobre o feed-back remodelador da exposição a uma língua dominante, vista como superior, da escrita-ortografização, onde impera a língua dos dominadores, sobre a língua oral, não apenas pela entrada avassaladora de elementos lexicais, cada vez mais intraduzíveis, mas também pela sutil penetração de novos elementos gramaticais. Mutua Mehinaku, o primeiro 'índio de aldeia' a obter título de mestre em antropologia, descreveu, com brilho próprio, a língua tetsualü² ('misturada') das jovens gerações kuikuro, alfabetizadas, escolarizadas, consumidoras de mídias e tecnologias, em seus discursos e conversas, jogando futebol, em reuniões, na internet (Mehinaku, 2010). ${ }^{3}$

O pesquisador é um 'escriba' responsável pelo surgimento de 'escribas' indígenas. Entre as lembranças das primeiras fases do 
trabalho de campo, iniciado entre os Kuikuro do Alto Xingu em 1977, há uma cena recorrente, quase obsessiva: a interação silenciosa entre um kagaiha ('Branco') que ouve e escreve e kuge ('gente alto-xinguana') que falam e observam ${ }^{4}$. Passava horas transcrevendo palavras, frases, narrativas, diálogos, em uma ortografia para meu próprio uso e consumo, baseada numa análise fonética e fonológica ainda incipiente. A tradução, do Kuikuro para o Português e vice-versa, procedia automaticamente e penosamente, esbarrando em incompreensões e equívocos, sempre no limite da aproximação possível. Foi somente ao longo da elaboração de minha tese (Franchetto, 1986) que a consciência da mutilação e da redução, que caracterizam a transformação da fala em escrita, aflorou dramaticamente, sobretudo quando redigi a parte dedicada à diversidade de registros e estilos que perpassam narrativas, discursos cerimoniais, a retórica política.

Toda língua natural humana tem, na sua realização falada, um ritmo, uma melodia, escandidos pelos agrupamentos silábicos, pelas estruturas métricas (do domínio da palavra aos domínios do sintagma, da frase, do enunciado). O ritmo da língua-fala é transfigurado nos ritmos do narrar e, mais ainda, na fala cantada das execuções rituais públicas e nos cantos. Inspirei-me nas propostas de autores como o pioneiro Jakobson (1968), Tedlock (1983) e Hymes (2004), entre outros, para tentar reproduzir na bidimensionalidade da página alguns, poucos, traços da execução oral. Aqui estão apenas uns exemplos dessa tentativa e da constante frustração diante do resultado.

Em artigo anterior (Franchetto, 2000), enfrentei o desafio de transcrever e traduzir os discursos cerimoniais executados por ocasião das grandes festas intertribais do Alto Xingu, peças de fala cantada, em versos densamente paralelísticos e metafóricos. O desafio parecia invencível, sobretudo ao ler o que outros pesquisadores diziam: são discursos incompreensíveis. Consegui mostrar a beleza poética desses discursos e a celebração da história emblemática de cada grupo-aldeia encerrada em cada um deles. A 
tradução, contudo, continua muito aquém do que gostaria e do que deveria ser, pelo fato dos versos escritos serem uma pálida sombra do ritmo monotonal desses 'salmos' rituais, pelos termos eruditos, as sutilezas de modos, aspectos e marcadores epistémicos, os dêiticos, as referências no espaço e no tempo, a retórica em que se entrelaçam o enaltecimento do passado, a inferiorização do presente na autoridade disfarçada da voz do chefe que discursa, uma voz coletiva e individual ao mesmo tempo ${ }^{5}$ :

taloki geleha atsakugake ngingoku anetaõ imalüa atsakugake ngingoku ünago imalüa geleha atsakugake ngingoku intela atai hüle atsakuhotagü ngingoku Angahuku kaenga atai hüle atsakuhotagü ngingoku itseke heke geleha ngapa igei wãke imagü apogui geleha ngapa igei wãke Kuhikugu igegatühüg $\dot{i}$ ateheha ngapa igei wãke

por nada continue correndo, mensageiro! não é pelo caminho de chefes, corra mensageiro! não é pelo caminho destes, corra, mensageiro! não é por aqui que deveriam correr os mensageiros no tempo em que era no rumo de Angahuku todavia deveriam correr os mensageiros eu sei que estavam lá os hiper-seres (os Brancos) eu sei que aquele era o caminho porque eu sei que eram de Kuhikugu os que eram levados

A vida kuikuro é atravessada por akinhá, 'narrativas': memória, explanação, caminhos de compreensão, sedimentação cosmológica, construção de personagens emblemáticas, transmissão de conhecimentos. A arte dos akinhá oto ('mestres do narrar') é a arte do ritmo dos paralelismos, da costura calma e progressiva que mantém o enga (caminho, base) através de sucessivos itsikungu, 
desvios, comentários, o diálogo necessário entre o narrador e seu itütsüingi, ' respondedor' (Franchetto, 2003).

Imbe opogipügü - Origem do pequi ${ }^{6}$

ainga telüko

Agagati hitsaõ tetagü kuigi andati

titaha egei

kuigi kilü hata

ihatuko hata

Ihogijüko leha

isinügü

tahinga enhügü

kuigi kilü hata ihekeni

eté Sakangatü tepügü

isilü

endihegiku

mbüngaitsü

ihangapugu teh hehe

foram para a roça

as esposas de Agagati estavam indo para a plantação de mandioca

uma vez lá

enquanto desenterravam as raízes de mandioca

enquanto tiravam a mandioca

(ele) as encontrou

Veio

Jacaré chegou

Enquanto desenterravam as raízes de mandioca

Sakangatü foi com sua beleza 
Com seu colar

Com seu colar de caramujo

Com suas braçadeiras

Com seus brincos, que beleza!

Este é o trecho inicial de uma akinhá ekugu, uma das narrativas 'verdadeiras' que contam da origem do que existe para os homens. O ritmo estruturado pela respiração, as pausas, a entonação, as mudanças de altura da voz, os ideofones, os gestos lentos do narrador deitado em sua rede, a pontuação discreta do 'respondedor', são todos elementos expurgados da escrita e irrecuperáveis, apesar da separação em linhas, ritmo dos versos, e das indentações, as alturas da voz que distinguem os eventos em primeiro plano dos da cena de fundo. A tradução é a última de muitas, na superação progressiva das aporias da redução escrita e das limitadas competência linguísticas na 'língua do outro’ de tradutores indígenas e do próprio pesquisador.

Alfabetizei o primeiro kuikuro, um adolescente em reclusão pubertária, em 1980. Participei da formação dos primeiros professores indígenas nos anos 90. Sou responsável pelo aparecimento da primeira geração de 'escribas' ou escritores indígenas em sua língua materna ${ }^{7}$. Produzimos livros. Alguns destes continham akinhá, dada a expectativa dos chamados 'formadores' de professores indígenas, dos cursos de magistério aos do ensino superior, e sua insistência, de que o exercício da escrita deve se dar, preferencialmente, na produção de 'estórias tradicionais', 'mitos'. Tendo como modelo uma prosa simplória e infantil, eis como desaparece a arte narrativa da execução de uma akinhá:

Agagati hitsaõ telü kuigi andati. Tita, kuigi kilü hata, tahinga heke hogijüko. Isinügü, isilü, mbüngaitsü, ihangapugu. 
As esposas de Agagati foram para a roça. Lá, enquanto tiravam a mandioca, Jacaré, enfeitado com colar, braçadeiras e brincos, as encontrou.

A decisão dos professores kuikuro de não escrever mais akinhá assim, para e na escola, chegou quando a consciência da mutilação se associou à recusa de passar longas horas ouvindo o akinhá oto, transcrevendo, reduzindo, traduzindo. Este trabalho só começava a ter algum sentido quando encomendado (e pago) pelo pesquisador. Este foi o início de uma nova fase para os tradutores kuikuro e a intensificação e refinamento do trabalho de tradução.

\section{Escrever e traduzir para a escola e para o pesquisador}

O projeto de documentação da língua falada pelos Kuikuro, com seus gêneros e artes verbais, iniciado em $2001^{8}$, resultou na formação continuada de tradutores indígenas, que aprenderam a ouvir atentamente gravações, transcrever com cuidado o que ouviam, experimentar traduções para uma língua ainda pouco conhecida. Jamalui se considera, hoje, um tradutor profissional; seu irmão, Mutua, se lançou na aventura de se tornar um pesquisador de suas próprias língua e cultura. Jamalui é um tisakisü oto ('mestre das nossas palavras'), como seu falecido avô materno, o primeiro a entender e falar português, intérprete de viajantes, indigenistas, antropólogos, desde a década de 40 , anos de sua juventude. Jamalui se destaca entre os consultores indígenas do projeto e de minhas pesquisas e me acompanha há pelo menos dez anos. Eis a reprodução de duas páginas de um de seus muitos cadernos: 


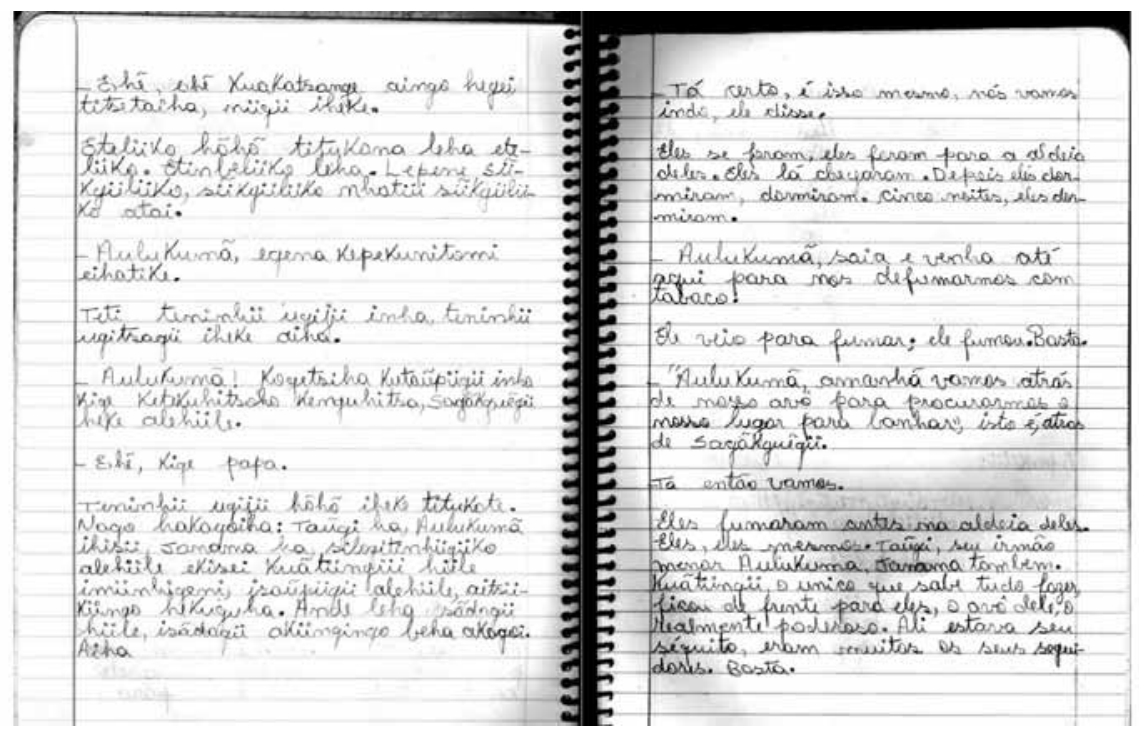

À esquerda está a transcrição, feita em 2002, de uma narrativa mítica - tuã etihuntepügü, 'origem das águas' -, à direita a tradução. Observe-se a marcação dos diálogos, que constituem não menos do que a metade de qualquer narrativa, o uso da pontuação, a divisão em parágrafos. O modelo do texto em prosa é, todavia, ainda presente; Jamalui tinha passado pela escola, onde nada se fala da poética da arte de narrar ou de qualquer poética indígena.

É impressionante a distância entre este exercício de escrita-tradução e os primeiros ensaios de escrita dos professores indígenas em formação. Veja-se o que um grupo deles - falantes do outro dialeto da Língua Karib Alto-Xinguana - produziu em 1994, ano do primeiro curso de magistério no Xingu, quando lhe foi pedido para 'escrever' a narrativa ana otsogitsügü, ' origem do milho'. 


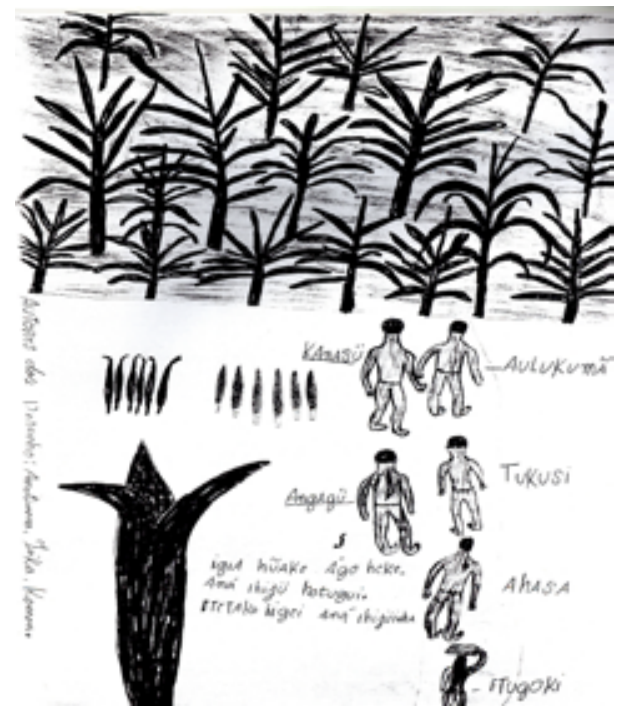

Aqui temos um exemplo de coexistência de pictografia e escrita. A pictografia, em suas diversas manifestações, esteve presente em muitas sociedades ameríndias, e ainda sobrevive em algumas delas. Ela não deve ser pensada como uma pré-escrita, mas como uma outra escrita, uma entre todas aquelas representações não-alfabéticas que foram geradas e usadas em momentos distintos, em contextos específicos, para diversos fins, na história dos povos nativos das Américas 9 .

Os elementos centrais da narrativa, do ponto de vista de uma possível 'leitura' por parte dos autores indígenas e de seu público indígena virtual, estão neste desenho-escrita. A narrativa está condensada em dois planos horizontais: o plano superior é coberto pelo ' desenho' de uma plantação de milho, o lugar da transformação mítica. O plano inferior é por sua vez organizado em 'linhas' verticais: na parte à direita, os resultados da transformação (diferentes tipos de milho e a origem dos pelos pubianos das mulheres a partir da palha das espigas queimadas); na parte à esquerda, estão os personagens transformadores com seus nomes e dispostos em 
uma sequência vertical, precisa, de dois pares seguidos por indivíduos, todos pertencentes ao (não)tempo das origens, e uma frase escrita em língua indígena que diz "assim, naquele tempo, eles mexiam com o milho, em primeiro lugar, eles iam para mexer com o milho".

Essa fusão criativa - e realmente inter-cultural - de modalidades de expressão (orto)gráficas foi, em poucos anos de escolarização, substituída pelo monocromatismo das linhas paralelas que cobrem a página do caderno ou do livro. É o que vemos nas duas reproduções abaixo: a transcrição 'livre', manuscrita, da mesma narrativa realizada pelo professor Amatiwana Matipu em 1997, transformada em seguida em texto digitado, editado e publicado em um livro para uso escolar, sucessivas operações de redução com eliminação de repetições, paralelismos e muitos outros elementos narrativos considerados 'supérfluos' ou redundantes ${ }^{10}$.

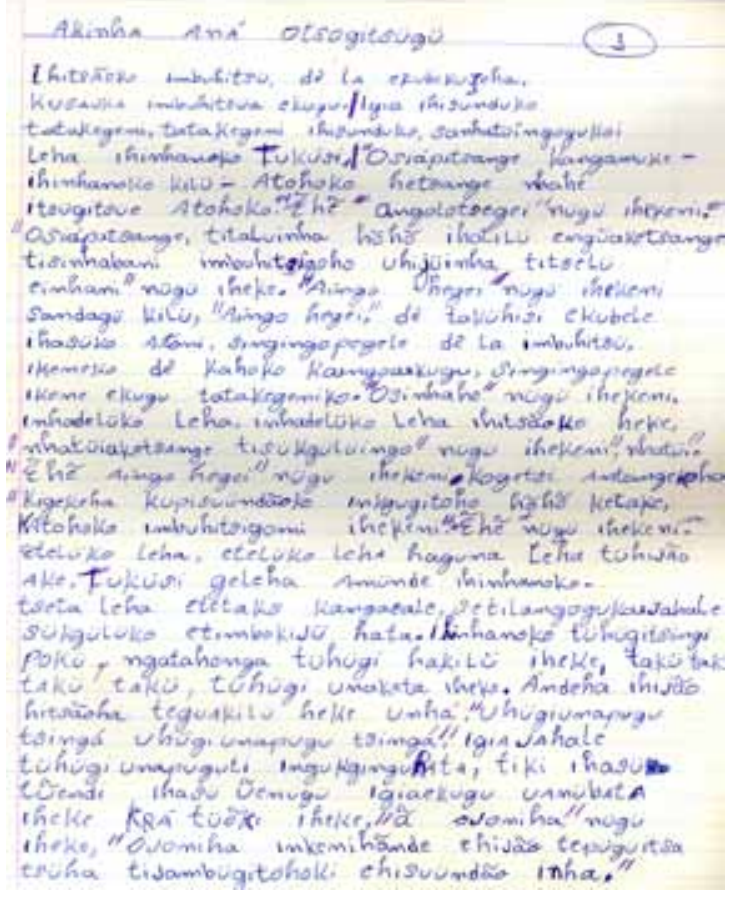




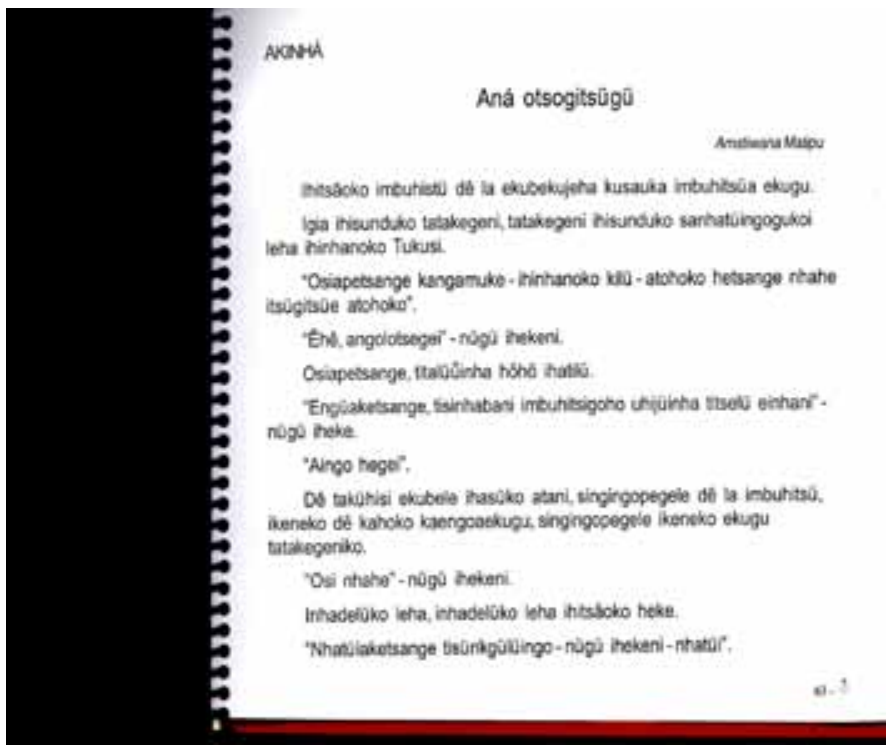

Vários desafios são comuns ao tradutor indígena e ao pesquisador-tradutor não-indígena. Quero abordar brevemente dois dentre eles.

O primeiro concerne a transcrição e tradução de cantos kuikuro ${ }^{11}$, especialmente dos tolo, cantos femininos que 'traduzem', em palavras e outra música, peças de música das flautas kagutu tocadas exclusivamente pelos homens. Trata-se já de uma tradução como transformação entre dois gêneros musicais aproximados num trans-gênero. Os cantos tolo têm uma origem narrada em um registro intermediário, na passagem entre o mítico e o histórico, colocando em questão a agência humana ordinária, feminina, que colocou 'letras' nas músicas de flautas.

Os cantos tolo são "feitos ir para alguém" (tolo-te-, tolo- verbalizador transitivo com beneficiário). Em geral, eles são enviados pela protagonista/compositora para seu amante. São cantos que falam de paixão, ciúme, sedução, vingança, saudade, cenas em 
pinceladas, fotogramas, que deixam intuir uma estória sempre presente na memória das mulheres eginhoto ('mestres dos cantos'), quando não também de seus ouvintes. A cantora, que atualiza o canto, cita uma fala-mensagem. Em alguns cantos mais complexos, pode-se ter uma estrutura de citações encaixadas (i.e. citações de citações): uhisü kilü uheke hegei, "eu disse para o meu jovem irmão/primo/amor”, verso que emoldura as citações encaixadas no canto. É o caso do canto abaixo, apresentado primeiro na última das minhas transcrições e traduções, depois na transcrição e tradução de Jamalui (2012):

I.

tuãka kete

uhisü kilü uheke

uhisü kilü uheke

utalitsügü kuNtzonkgitomi

vamos banhar

disse para mim o meu amor

disse para mim o meu amor

umüngitsügü kuNtsonkgitomi

(disse) lave-me e tire meu urucum

uhisü kilü uheke hegei

(disse) lave-me e tire meu cheiro de copaíba

disse para mim o meu amor

II.

tuãka kete uhisü kilü utalikugu kundzonkgitomi umüngisü kundzonkgitomi uhisü kilü uheke egei

vamos banhar, disse meu primo vamos lavar meu óleo de copaíba vamos lavar meu urucum disse meu primo

A transcrição resgata somente a letra do canto sem transcrição musical, transforma o canto em poema ${ }^{12}$. Utilizamos alguns recursos clássicos para dar uma ideia, ainda que imperfeita, da melodia: linhas/versos, mais ou menos coincidentes com linhas melódicas; indentação das linhas para render jogos decrescentes de altura tonal. A transcrição pode preservar, ou eliminar, as repetições. Nes- 
te último caso, ela é, digamos, minimalista. Quando completa, é possível depreender paralelismos e variações, versão indispensável para dialogar com as estruturas propriamente musicais dos cantos tolo e das peças kagutu.

Se na comparação entre as transcrições-traduções do canto anterior, feitas por mim e por Jamalui, se nota, na primeira, uma menor parcimônia e um maior empenho poético, na que se segue, Jamalui se revela bem mais preciso na tradução:

Eegete uotonu ehüneke ehüneke

Ahitalogute uotonu ehüneke ehüneke

Makaigi kengüa uotonu ehüneke ehüneke

Tradução de Jamalui:

Ali eu senti sua falta, sua falta

No rio reto de Ahita, senti sua falta, sua falta

Onde Bakairi assassinou pessoa, senti sua falta, sua falta

Minha tradução:

Lá eu senti saudade de você

Em Ahitalogu eu senti saudade de você

Nos Bakairi eu senti saudade de você

E aqui está uma possível 'fusão' das duas traduções:

Lá eu senti sua falta, sua falta

Onde corre o rio reto de Ahita, senti sua falta, sua falta

Lá onde Bakairi matou gente, senti sua falta, sua falta

Um segundo desafio para a tradução de qualquer língua, mais agudo no caso de línguas ameríndias, é o de termos intraduzíveis (Franchetto, 2002). Como glosar e descrever, por exemplo, os ter- 
mos itseke ou akunga? Itseke é 'espírito' (tradução corriqueira), 'Bicho' (tradução local), hyper-ser (tradução minha, já que todo itseke é algo kuegü)? Akunga é 'alma', 'sombra', duplo', 'sopro'? E tem várias akunga...Cada uma dessas palavras evoca uma inteira cosmologia, apreensões do que é vida, morte, corpos. São categorias ao mesmo tempo salientes e, para nós, aparentemente vácuas, tradução inalcançável. Seus significados são inefáveis para os falantes e é um equívoco pensar que todas as categorias possam ser representadas por uma definição e que esta definição seja compartilhada; é este o caso de muitas categorias não-observáveis. Não todos os significantes possuem uma sua contraparte conceitual fixa e delimitada. Como diz Boyer (1992), o vocabulário de uma língua natural não é uma paisagem uniforme. Descrições interpretativas, definições e comentários nativos podem suprir, em parte, a pobreza de nossas ferramentas linguísticas e nos limites de nossa compreensão; assim, qualquer tradução 'séria' deveria se tornar uma edição crítica, qualquer dicionário deveria conter súmulas etnográficas. A escrita que resulta do transcrever-traduzir não suporta, todavia, esse peso, esse abismo de camadas entre a língua-fonte e a língua-alvo. Ao contrário, ela pode ser um depurador radical, aniquilador.

\section{Traduzindo para missionários}

O cuidado que demandaria uma tradução que parte do respeito à língua-fonte é algo propositadamente manipulado na tradução missionária. De um lado, domina o esmero em adequar a língua indígena, forçosamente, à língua-alvo, sendo esta realizada em um texto escrito considerado 'sagrado' e absoluta e universalmente 'verdadeiro', por sua vez resultado de várias traduções; do outro, o intento de trabalhar com um tradutor indígena, ao lado do missionário, é o de garantir que o texto-mensagem-fonte chegue compreensível em seus significados e sentidos ao leitor da língua-alvo. 
$\mathrm{Na}$ escola, oficializa-se o código restrito de uma expressão escrita monitorada, reproduzido na chamada 'literatura indígena', obra missionária. Esmorece o código elaborado das artes verbais da tradição oral. Em outras palavras, o tratamento dado às narrativas tradicionais, rebaixadas a 'contos' ou 'lendas', contrasta com tratamento de excelência dado aos textos cristãos. Às primeiras se aplica uma operação de redução, que redunda em empobrecimento e infantilização; às segundas se aplica, ao contrário, uma operação de tradução fiel, com todos os cuidados da exegese e da transposição por equivalências sintáticas e semânticas. $\mathrm{O}$ resultado acaba contradizendo, e desmistificando, a retórica do refrão 'escrita a serviço do resgate'. Os índios leitores elaboram rapidamente uma comparação entre seus mitos exprimidos e banalizados - um folclore de pequenas ficções - e os grandes mitos dos Brancos consagrados em verdadeiros livros. Enfim, aos primeiros se destina o código restrito da chamada 'literatura indígena' e o termo 'mito' com as conotações negativas do senso comum; aos segundos, nem literatura nem mitos, se destina o código elaborado da Palavra Revelada, 'estória-história verdadeira'.

Muitos dos tradutores indígenas em atividade passaram por essa experiência ou continuam a serviço de missionários dedicados a traduzir bíblia e evangelhos nas línguas do mundo, dos povos 'pagãos' de tradição oral (Franchetto, 2008).

Lembrar São Jerônimo ou a Bíblia Sagrada Polyglotta escrita por Brian Walton e publicada em 1657 é lembrar que a tradução cristã é um protótipo fundador. A flexão pentecostalista do empreendimento missionário evangélico faz da poliglossia e da tradução interlingüística um princípio e uma prática, com suas interfaces com a redução à escrita de línguas ágrafas e com a educação bilíngüe, um mesmo aparelho de assimilação e cristianização. Se comparada à rigidez e ao purismo católicos diante do texto 'sagrado', a postura evangélica, paradoxalmente, legitima as línguas indígenas.

$\mathrm{Na}$ visão pentecostalista, o poder de dominar as equivalências entre palavras e expressões de línguas distintas são os "dons" mais 
importantes do cristão iluminado pelo Espírito Santo. A tradução se dá num longo processo que batiza uma nova escrita, envolvendo tradutores e consulentes de tradução, os fiscais da escrita (Stoll, 1982; Barros, 1993) e a aliança entre missionário-linguista e tradutores indígenas coloca escrita e tradução a serviço de outra tarefa, a ' civilização', a conversão, instigadora de mudanças culturais e sociais.

Vejamos a guisa de exemplo, um pequeno trecho da tradução do Evangelho segundo Lucas em Kuikuro ${ }^{13}$ :

26. Ora, no sexto mês, foi o anjo Gabriel enviado por Deus a uma cidade da Galiléia, chamada Nazaré;

27. a uma virgem desposada com um varão cujo nome era José, da casa de Davi; e o nome da virgem era Maria.

28. E, entrando o anjo onde ela estava, disse: Salve agraciada, o Senhor é contigo.

29. Ela, porém, ao ouvir estas palavras, turbou-se muito e pôs-se a pensar que saudação seria essa.

30. Disse-lhe então o Anjo: Não temas, Maria; pois achaste graça diante de Deus.

Tradução em Kuikuro:

26. Aetsi leha inkgugetoho Isabeu nohandühügü ngunegü atai, Deusu heke anju Gabigieu humilü ete Nazagena, Galileia ngongogu tongona

27. itaginhundomi Magia ake, daunke tikumbüngü gele otomo ngihatügüha Juse ake inhotundomi, anetü Dafi higü kuegüpeha ekisei.

28. Anju inhügü leha hakila iheke nügüha iheke: "Magia tügekuili eitse, Deusu heke naha aküngipügü. Ake leha Deusu Itsanginhügü eigatitsegomi iheke, ahetinhombatomi gehale!".

29. Magia hekeha egea anju kilü talütse ingugi, akungakilü leha iheke, etinenügü leha teleginügü heke: "Uã nile egei nügü hungu iheke?". 
30. Anju kilüha iheke: "Ojoha einegetu Magia! Deusu ngaküngipügü egei!"

Notamos as torções para chegar a equivalências entre termos e expressões culturalmente distantes: 'virgem' é daunke tikumbüngü, 'jovem recém egressa da reclusão pubertária que não teve relações sexuais'; 'José da casa de Davi' é anetü Dafi higü kuegüpeha, 'hiper-neto (descendente) do chefe Davi'. E assim por diante. Há, porém, algo bem mais perturbador: a ausência de qualquer instância de marcadores epistêmicos que qualificam a fonte e a cadeia de transmissão da informação, a atitude do falante diante do seu dito. Toda narrativa kuikuro é pontuada por esses marcadores, e estes traçam as fronteiras sutis entre relatos míticos, cujo valor de verdade é o mesmo de um testemunho em primeira pessoa e visual, e relatos de fatos guardados nas memórias coletivas ou familiares ${ }^{14}$. Trata-se da expurgação de tudo o que pode caracterizar a narrativa evangélica, cristã, como um dizer humano e não como 'palavra revelada' divina, original e absolutamente verdadeira.

\section{Considerações finais ${ }^{15}$}

Todo ato de compreensão é um ato de tradução (e vice-versa); em outras palavras, algum processo de tradução é inerente ao ouvir, ao falar para outro, ao interpretar pensamentos e palavras alheias, ao comunicar os próprios pensamentos e palavras. Este exercício é um desafio aos limites da compreensão quando pretendemos traduzir línguas 'outras', distantes, como são as ameríndias. Para começar, elas nos impõem uma dupla torção, já que a transformação do oral ao escrito precede a tradução propriamente dita. Em segundo lugar, o caminho é quase sempre unidirecional, na ausência de uma atividade tradutiva em sentido inverso, para a língua indígena como alvo, e não apenas como fonte. A tradução, nesse campo, tem raramente o cuidado e a sofisticação que dedica- 
mos à tradução literária ou científica: é improvisada, grosseira, os erros e equívocos podem permanecer desconhecidos, o resultado é um texto na língua-alvo simplório, soluçante. Quando feita em sentido inverso, como na tradução missionária, o resultado é um texto numa língua desencarnada.

Traduzir línguas indígenas nos ameaça com a sua impossibilidade: um absurdo epistemológico, como diz Steiner (1975). Lembramos o pessimismo relativista de Sapir (1921): não existem duas línguas que sejam suficientemente semelhantes ao ponto de ser consideradas como representantes da mesma realidade social; os mundos em que vivem sociedades diferentes são mundos distintos, não apenas o mesmo mundo com dois rótulos. Jakobson (1959) fala da impossibilidade da equivalência completa entre sistemas linguísticos (e culturais), sua intrínseca diversidade e não-adequação, condicionados por fatores extra-linguísticos, às vezes inconciliáveis. Ortega y Gasset (1967) enfatiza que no domínio intelectual não há atividade mais humilde, embora resulte ser exorbitante: "um ser que não fosse capaz de renunciar a dizer muitas coisas, seria incapaz de falar. E cada língua é uma equação diferente entre manifestações e silêncios. Cada povo cala algumas coisas para poder dizer outras. Porque tudo seria indizível. Daí a enorme dificuldade da tradução: nela se trata de dizer em um idioma precisamente o que este idioma tende a silenciar”.

A tradução ideal, compreensão total, é impossível, mas, como diz Coseriu (1997), é exatamente a incongruência entre as línguas - por sua diversidade estrutural em gramática e associação entre formas e significados - o móvel básico da atividade de tradução. E traduzir é uma pulsão irreprimível, além de uma necessária realidade empírica. Então, só nos resta desafiar o paradoxo e comungar humildade (Paes, 1997) e ousadia: a humildade que nos faz abandonar a pretensão da equivalência para procurar aproximações 'felizes'; a ousadia de não se esconder atrás da suposta transparência ou invisibilidade do tradutor. Nesse sentido, a tradução de (ou para) línguas ameríndias é uma negociação também entre traduto- 
res, que dominam diferentemente as línguas em confronto e seus contextos de enunciação.

O trabalho de tradução é um exercício sem fim, sempre sujeito a novas versões e aperfeiçoamentos. Suas dores e delícias são temas da reflexão de poetas como Rothemberg (1992) e Bringhurst (1999).

Para Rothenberg, traduzir não é um ato mecânico para o qual existam regras prontas a serem aplicadas, mas, ao mesmo tempo, é um trabalho preciso e contido nos limites da língua/texto-fonte. Se considerarmos que estamos lidando com poesia (o que, no caso das peças de fala cantada ameríndia, é uma questão, não uma constatação), temos que estar prontos a quebrar os limites que nos mantêm distantes do poema. Tradução é movimento, de uma língua a outra, do passado ao presente, é um comentário sobre o outro e o mesmo e sobre sua diferença. Tradução é transformação.

No exercício penoso de equilibrar-se entre a literalidade e a interpretação, a tradução deve ser capaz de apontar, sobretudo, as potencialidades do original e de suas formas, às vezes escondidas, de poética. A tradução é perigosamente ativa; participa da construção de um nexo cultural. Transforma e revela.

Quando o poema/canto é vivo e existe alhures, como pode ele ingressar na tradução e na escrita? O texto está diante de nós, está entre nós e a fonte, torna-se a nossa fonte. É este o ponto em que a literalidade desaparece e $o$ ato da tradução se torna um ato poético. Não há literalidade nem cópia, mas uma relação irônica com a fonte primária que pode ser duplicada na experiência, mas não na linguagem. Cada tradução é um registro desta divergência, um comentário sobre a falência de ser fonte. Podemos comentar sobre a fonte, mas sem a força e o poder que esta tem.

Como os cantos haida, traduzidos e interpretados por Bringhurst, os cantos tolo kuikuro nos surpreendem por sua economia e sutileza. Há neles uma lógica da imaginação - poética e música não estão, ainda, separadas. Uma linguagem onde a unidade é não a sentença da prosa, nem a linha métrica, mas uma espécie 
de respiro-pensamento ou frase musical. Bringhurst fala de uma "prosódia noética", para ele mais importante do que a prosódia sonora. A prosódia noética deve estar subjacente à prosódia visual da transcrição e da tradução, para que se escute a música silenciosa de imagens e temas. No poema-canto o que há para ser pensado se funde com o que há para ser ouvido.

Tudo isso ecoa em mim ao traduzir narrativas e cantos kuikuro, sinto-me muito aquém do possível, faço as contas com a melancolia do qual nos fala Benjamin. Por outro lado, excita-me a ideia de que a exposição de textos escritos e traduções pode engatilhar o surgimento de novos gêneros literários, enriquecendo o que existe. Excita-me a ideia de poder quebrar certos horizontes da língua-alvo ${ }^{16}$, provocar suas possibilidades a partir de um conhecimento analítico - métier do linguista - da língua fonte, condição sine qua non de uma maior sensibilidade e de um maior respeito diante dela.

\section{Notas}

1. O curso foi dado no Programa de Pós-Graduação em Antropologia Social do Museu Nacional, Universidade Federal do Rio de Janeiro. Os seminários foram: (1) Kristine Stenzel e Bruna Franchetto, "A gênese de escritas e ortografias para línguas indígenas”; (2) Márcia Dámaso Vieira e Oiara Bonilla "Aspectos da língua Paumarí e problemas de tradução"; (3) Rosângela Pereira de Tugny e Sandro Campos, "A língua dos cantos Maxakali: desafios para a tradução"; (4) Pedro de Niemeyer Cesarino, "Narrativas e cantos Marubo: uma experiência de tradução etno-poética"; (5) Márcia Nascimento, falante da língua Kaingang e mestranda em Linguística da UFRJ, "Reflexões sobre a tradução missionária"; (6) Jamalui Mehinaku, falante da língua Kuikuro, tradutor: "As experiências de um tradutor indígena”. Os seminários, gravados em vídeo, serão em breve acessíveis na web. 
2. A transcrição dos termos kuikuro é aqui ortográfica, baseada no sistema gerado ao longo da análise linguística e da própria formação de professores indígenas, usada na alfabetização, na escrita das gerações alfabetizadas e na produção de materiais variados para as escolas indígenas. O grafema $\ddot{u}$ representa uma vogal alta entre central e posterior, não-labial; o grafema $g$ representa um flap uvular; os dígrafos $n g$, a consoante nasal velar, e $n h$ a consoante nasal palatal (como em português).

3. A maior parte de minhas pesquisas linguísticas e etnográficas foi realizada junto aos Kuikuro, cerca de 600 índios falantes de uma variedade da Língua Karib Alto-Xinguana, um dos dois ramos meridionais da família karib, e que vivem, hoje, em seis aldeias na porção sudeste da Terra Indígena do Xingu, Mato Grosso. Kalapalo, Nahukwá e Matipu são outros grupos karib vizinhos dos Kuikuro e falam outra variedade da mesma língua.

4. O termo kuikuro que designa o ato de escrever ou a própria escrita é ahehijü, cujo significado primário pode ser traduzido com 'traçar mapas, esquemas, modelos no chão, areia, e outro suportes, inclusive no papel'. Mesmo sem conhecer esta palavra, Steinen fala de várias modalidades dessa expressão e comunicação gráfica no Alto Xingu, no final do século XIX, bem antes da chegada da escrita (Steinen, 1894, Cap. X). Ahehijü designa, hoje, também o ato de fotografar ou de filmar. É interessante notar a excepcionalidade dos Karib alto-xinguanos no panorama ameríndio ou, melhor, amazônico, e até mesmo se comparados com os alto-xinguanos falantes de línguas tupi ou arawak. A partir de dados esparsos nas etnografias existentes e de trabalhos que tratam das concepções ameríndias em torno da escrita (alfabética), ahehijü encerra uma representação de natureza 'profana' que se contrapõe a outra, xamânica, mais geral e dominante (Gow, 1990; Collet, 2006; Lagrou, 2007; Macedo, 2009, entre outros). Nesta última, escrever ou escrita está associado aos grafismos transmitidos aos humanos por seres míticos e originários, objeto de visões e sonhos e que transformam corpos e objetos sobre os quais são reproduzidos.

5. Transcrição da execução do chefe Tahukula em 1996.

6. Narrativa contada por Nahu em setembro de 1981 na aldeia kuikuro de Ipatse.

7. O leitor pode se perguntar por que uso, de novo, o termo 'escriba' e a resposta é que, de fato, os que se expressam através da escrita e produzem textos em língua indígena pertencem a um grupo, na maioria professo- 
res, leitores e mediadores diante da maioria não letrada ou que não usa a escrita fora do âmbito escolar. A escrita e a escolarização produziu um novo segmento social, na fronteira com o mundo dos brancos, com novos privilégios e poderes.

8. O Projeto de documentação da Língua Karib do Alto Xingu ou Kuikuro foi financiado pela Fundação Volkswagen no âmbito do programa de documentação de línguas ameaçadas (DOBES) e contou com apoio do Instituto Max Planck de Psicolinguística, de 2001 a 2006. O trabalho de documentação continua até hoje, cada vez mais nas mãos dos próprios pesquisadores indígenas. Entre os resultados da documentação está um acervo digital com mais de 200 'sessões' (eventos de fala de diferentes gêneros verbais, transcritas e traduzidas), imagens, mapas, documentos e textos,

9. Em Severi (2004), Déléage (2009) e Cesarino (2011) são trabalhos recentes e instigantes sobre as formas de outras 'escritas', pictográficas e não alfabéticas, passadas e atuais, na América indígena.

10. Tisügühütu, Kukügühütu. Livro de leitura e atividades de escrita na língua Kalapalo/Nahukwá/Matipu. São Paulo: Instituto Socioambiental. 2002, p. 63.

11. Até o momento, Tugny (2009a, 2009b, 2011), Maxakali \& Rosse (2011) e Cesarino (2011) são, ao que eu sei, os únicos autores, no Brasil, que realizaram um trabalho de tradução de artes verbais e cantos indígenas fundamentado em um considerável conhecimento etnográfico e inspirado por uma aproximação etno-poética entre a língua-fonte e a língua alvo.

12. Em Fausto et al. (2011) e Franchetto \& Montagnani (2011) estão os primeiros resultados da colaboração entre antropólogo, linguista e etno-musicólogo, com descrição e análise das complexas relações sonoras entre artes verbais e música kuikuro e, especificamente, entre músicas das flautas kagutu e cantos tolo.

13. A atuação de missionários evangélicos, principalmente da JOCUM (Jovens com uma Missão), na região do Xingu é relativamente recente; junto aos kuikuro começou no final dos anos 90. As sessões de tradução acontecem na cidade de Canarana, próxima às fronteiras da área indígena, na casa dos missionários. Os missionários se apropriaram da ortografia e da descrição gramatical desenvolvida pelos linguistas e pelos professores indígenas, pagam o tradutor em dinheiro por 
hora de trabalho. Hoje circula impresso em língua kuikuro o Evangelho segundo Lucas e um filme sobre a vida Jesus dublado em Kuikuro (o original é em inglês e foi produzido décadas atrás).

14. Para uma descrição e análise de alguns dos marcadores epistêmicos em Kuikuro, ver Franchetto (2007). Basso (2008) apresenta uma descrição ampla do mesmo fenômeno em Kalapalo.

15. O livro de Eco (2003) me acompanha nestas conclusões.

16. Imaginando esses horizontes, penso em Derrida (1995): tradução e 'texto' original são, ambos, criações num mesmo nível, onde se torna possível a contaminação entre línguas e significados. A tradução instaura uma diferença com relação a sua própria língua, que renasce, assim como o original transformado.

\section{Bibliografia}

BASSO, E. B. (2008): "Epistemic Deixis in Kalapalo". Pragmatics, Vol. 18, n. 2 (2008).

BENJAMIN, W. (2000) : "La tâche du traducteur". In: BENJAMIN, W. Oeuvres I. Paris: Gallimard, p. 244-262.

BOYER, P. (1992): Tradition as Truth and Communication. Cambridge: Cambridge University Press.

BRINGHURST, R. (1999): A Story as Sharp as a Knife. Vancouver/Toronto: Douglas and McIntyre; Lincoln: University of Nebraska Press, p. 361-371.

CESARINO, P. (2011): Oniska. Poética do Xamanismo na Amazônia. São Paulo: Perspectiva. 
COLLET, C. (2006): Ritos de Civilização e Cultura: a escola Bakairi. Tese de Doutorado em Antropologia Social/ PPGAS/Museu Nacional/UFRJ.

COSERIU, E. Linguistica del testo. Roma: Carocci, 1987.

DERRIDA, J. (1987): “Des tours de Babel”. In: Psyché: inventions de l'autre. Paris: Galilée.

DÉLÉAGE, P. (2009). La croix et les hiéroglyphes. Écritures et objets rituels chez les Amerindiens de Nouvelle-France (XVII ${ }^{e}$-XVIII ${ }^{e}$ siècles). Paris: Éditions Rue d’Ulm/Presse de l’École Normale Superieure - musée di quai Branly.

ECO, U. (2003): Dire quasi la stessa cosa.: esperienze di traduzione. Milano: Bompiani.

FRANCHETTO, B. (1986): Falar Kuikúro. Estudo etnolinguístico de um grupo karíbe do Alto Xingu. Tese de Doutorado. Programa de Pós Graduação em Antropologia Social, Museu Nacional, UFRJ.

. (2000): "Rencontres rituelles dans le Haut Xingu: la parole du chef". Aurore Becquelin Monod e Philippe Erikson (orgs), Les Rituels du Dialogue. Promenades ethnolinguistiques en terres amérindiennes. Nanterre: Societé d’Ethnologie, (481-510).

. (2002): "How to Integrate Ethnographical Data into Linguistic Documentation: some remarks from the Kuikuro Project (DOBES, Brazil)". P. Austin, H. Dry e P. Wittenburg (orgs.), Proceedings of the International LREC Workshop on Resources and Tools in Field Linguistics. ISLE/DoBeS.

. (2003): "L'autre du même: parallélisme et grammaire dans l'art verbal des récits Kuikuro (caribe du Haut Xingu, Brésil)". Amerindia 28, numéro Langues caribes. Paris: AEA, p. 213-248.

. (2007): "Les marques de la parole vraie en Kuikuro, langue caribe du Haut-Xingu (Brésil)". In Z. GUENTCHEVA \& I. LANDABURU (eds), L'Énonciation médiatisée II. Le traitement épistémologique de l'information : illustrations amerindiennes et caucasiennes. Paris: Éditions Peeters, p. 173-204. 
. (2008): "A guerra dos alfabetos: Os povos indígenas entre o oral e o escrito". MANA. Estudos de Antropologia Social, Volume 14, número 1, abril de 2008. Museu Nacional - Departamento de Antropologia, Programa de Pós-Graduação em Antropologia Social, p. 31-59.

FAUSTO, C; FRANCHETTO, B; MONTAGNANI, T. (2011) : “Art verbal et musique chez les Kuikuro du Haut Xingu”. L'Homme 197, janvier/mars 2011, p. $41-70$.

FRANCHETTO, B. e MONTAGNANI, T. (2011): "Flûtes des hommes, chants des femmes. Images et relations sonores chez les Kuikuro du Haut Xingu". Gradhiva 13. Musée du quai Branly, Paris, p. 94-111.

GOW, P. (1990): “Could Sangama read?”. History and Anthropology, 5:87-103.

HYMES, D. H. (2004): "In vain I tried to tell you": Essays in Native American Ethnopoetics. University of Nebraska Press.

JAKOBSON, R. (1968): "Poetry of grammar and grammar of poetry", Lingua, 21: 597-609.

. (1959): "Linguistic Aspects on Translation".In BROWER R. (ed.), On Translation. Cambridge: Cambridge University Press, p. 232-239.

MACEDO, S. (2009): "Xamanizando a escrita: aspectos comunicativos da escrita ameríndia”. Mana vol.15 no.2 Rio de Janeiro Oct. 2009.

MAXAKALI, T; ROSSE, E. P. (2011): Kõmãyxop- cantos xamânicos maxakali/ tikmu'um. Rio de Janeiro: Museu do Índio-FUNAI.

MEHINAKU, M. (2010): Tetsualü: plralismo de línguas e pessoas no Alto Xingu. Diss. De mestrado. Programa de Pós-Graduçaão em Antropologia Social, Museu Nacional, Universidade Federal do Rio de Janeiro.

ORTEGA Y GASSET, J. (1983): Miséria y esplendor de la traducción. In: Obras completas $V$, Madrid: Alianza Editorial/Revista do Ocidente, p. 431-452. 
PAES, J. P. (1997): Tradução: a parte necessária. São Paulo: Ática.

ROTHEMBERG, J. (1992): “'We Explain Nothing, We Believe Nothing”: American Indian Poetry and the Problematics of Translation". In: Swann, B. (ed), On the Translation of Native American Literatures. Washington: Smithsonian Institution, p. 64-79.

SAPIR, E. (1921): Language. An Introduction to the Study of Speech. New York: Harcourt, Brace and Co.

SEVERI, C. (2004): Il percorso e la voce. Un'antropologia della memoria. Torino: Einaudi.

STEINEN K. (1894): Unter dern Naturvölkern Zentral Brasiliens. Reiseschilderung und Ergebnisse der zweiten Schingú-Expedition 1887-1888. Berlin: Geographische Verlagsbuchhandlung von Dietrich Reimer. Tradução brasileira: SHADEN, Egon. 1940. "Karl von den Steinen. Entre os aborígenes do Brasil Central”. Revista do Arquivo Municipal, Nos. 34 a 68.

STEINER, G. (1975): After Babel. London: Oxford University Press.

TEDLOCK, D. (1983): The Spoken Word and the Work of Interpretation. Philadelphia: University of Pennsylvania Press.

TUGNY, R P. (2011): Escuta e poder na estética Tikmu'un. 1. Rio de Janeiro: Museu do Indio Funai.

TUGNY, R. P. (Org.); Narradores Tikmu'un (Org.). (2009a): Mõgmõka yõg Kutex / Cantos do gavião-espírito. 1. ed. Rio de Janeiro: Azougue.

TUGNY, R. P. (Org.); Narradores, escritores tikmu'un do Pradinho (Org.). (2009b): Xũnĩm yõg kutex xi ãgtux xi hemex yõg kutex / Cantos e histórias do morcego espírito e do hemex. 1. ed. Rio de Janeiro: Azougue. 